\title{
ANOMALIAS EM PADRÕES DE REDES DE DRENAGEM COMO FATOR DE VERIFICAÇÃO DE NEOTECTÔNICA - UM ESTUDO DE CASO NAS SUB-BACIAS DO RIO MAMUABA-PB
}

\author{
Tamires Silva Barbosa ${ }^{1}$ \\ Vinicius Ferreira de Lima² \\ Max Furrier ${ }^{3}$
}

Resumo: Este trabalho pressupõe discorrer acerca da importância da análise de anomalias dos padrões de redes de drenagem em estudos de cunho neotectônico. Para a verificação de tais anomalias empregou-se como instrumentos primários os índices morfométricos RDE (Relação Declividade-Extensão) e RFAV (Razão Fundo/Altura de Vale), que serão utilizados para a análise geológico-geomorfológica das sub-bacias e para a detecção de evidências neotectônicas relacionadas às anomalias encontradas nos padrões da presente rede de drenagem. Foram selecionadas para a análise, as sub-bacias dos rios Jangada, Mundo Novo e do Grilo. Estas se encontram situadas sobre uma mesma litologia - a Formação Barreiras camada de rochas sedimentares mal consolidadas de idade miocênica, que se depositam mais ou menos horizontalmente. Por conta dessas sub-bacias apresentarem seus padrões de drenagem atípicos ao seu embasamento, como por exemplo, rios retilíneos e encaixados, padrões em treliça e formas assimétricas, surgiu a necessidade da verificação dos processos geomorfológicos que condicionaram a evolução de sua drenagem. Com a aplicação dos índices morfométricos RDE e RFAV, obteve-se nos resultados valores que indicam que a área sobre a qual as sub-bacias estão situadas, provavelmente, sofreu atividades tectônicas recentes.

Palavras-chave: índices morfométricos; neotectônica; bacia hidrográfica.

\section{Anomalies in Patterns of Network Drainage How Factor For Verification of Neotectonic - A Case Study in The Sub-Basins of Mamuaba River - PB}

\begin{abstract}
This work presumes to argue about the importance of anomaly analysis of patterns drainage networks in neotectonic studies. To check such anomalies were used how primary instruments the indexes SL (Relationship Slope-Length) and VF (Reasion Valley Floor/Valley Height), these indexes will be used for the geologic-geomorphologic analysis of sub-basins and for detection of neotectonics evidences associated the anomalies found in the current patterns drainage. For this analysis were selected the Jangada, Mundo Novo e Grilo subbasins, they are seated on same litology - the Formação Barreiras - layer of poorly consolidated sedimentary rocks of Miocene age, which settle more or less horizontally. Cuz these sub-basins present their atypical drainage patterns to your geology, such as straight rivers and asymmetrical shapes, appear the need of checking the geomorphological processes that conditioned the evolution this watershed. The application of morphometric indices RDE and RFAV resulted in values that indicate that the area over which the sub-basins are located, probably suffered recent tectonic activity.
\end{abstract}

\footnotetext{
${ }^{1}$ Mestranda em Geografia pelo Programa de Pós-Graduação em Geografia-PPGG. Centro de Ciências Exatas e da Natureza - CCEN. Universidade Federal da Paraíba - UFPB. E-mail: mires.ufpb@gmail.com

${ }^{2}$ Graduado em Geografia, Departamento de Geociências, Centro de Ciências Exatas e da Natureza - CCEN. Universidade Federal da Paraíba UFPB. E-mail: viniciusgeo_lima@hotmail.com

${ }^{3}$ Doutorado em Geografia (Geografia Física) pela Universidade de São Paulo, Brasil(2007). Professor Adjunto, Nível III da Universidade Federal da Paraíba. E-mail: max.furrier@hotmail.com DOI: 10.7154/RDG.2013.0026.0010
} 
Keywords: morphometric indices; neotectonic; watershed.

\section{INTRODUÇÃO}

O termo "neotectônica" foi empregado pela primeira vez em 1948 pelo geólogo soviético V. A. Obruchev, para definir os movimentos da crosta terrestre que se instalaram durante os períodos do Terciário superior (Mioceno e Plioceno) e do Quaternário, e que assumiram um papel decisivo na formação da topografia contemporânea (SAADI, 1993).

Hasui (1990) relaciona a origem do neotectonismo no Brasil à migração do continente sulamericano e consequente abertura do Atlântico Sul, iniciada no Terciário médio, e considera que essas movimentações ocorrem até os dias atuais. Entretanto, o interesse pelos estudos neotectônicos no Brasil só teve maior impulso a partir da década de 1970, pela necessidade ligada à construção de numerosas e gigantescas obras de engenharia civil, tais como as usinas hidroelétricas e nucleares (SUGUIO, 1999), assim, foram se desenvolvendo diferentes técnicas para esses estudos.

Selecionou-se para a presente análise um elemento do meio físico que, segundo Christofoletti (1980), se constitui em um processo morfogenético dos mais ativos na esculturação da paisagem terrestre - a bacia hidrográfica. Para Barrela et al. (2001), a bacia hidrográfica é definida como um conjunto de terras drenadas por um rio e seus afluentes, formada nas regiões mais altas do relevo por divisores de água, onde as águas das chuvas ou escoam superficialmente formando os riachos e rios, ou infiltram no solo para formação de nascentes e do lençol freático.

A bacia hidrográfica vem a ser uma das melhores ferramentas para a compreensão dos processos ocorrentes ao longo do tempo geológico, explicitando em sua própria morfologia os eventos sob os quais a mesma foi submetida, sendo eles de natureza climática, antrópica ou estrutural. Os processos ocorrentes nas bacias geram modificações nos perfis dos cursos d'água permitindo que a bacia se readapte às novas condições colocadas, adiquirindo certas anomalias em seu padrão de drenagem por conta de sua busca por novo equilibrio.

Segundo Etchebehere et al. (2004), a identificação de evidências de atividade neotectônica em terrenos do interior continental, que é o caso das sub-bacias em estudo, localizadas à retaguarda do litoral paraibano, onde o registro da sismicidade é pobre, ainda pode ser classificada como um esforço heurístico. Nesse sentido, o uso de índices morfométricos que 
exploram atributos relacionados aos perfis ou ao traçado dos cursos d'água apresenta um potencial relativamente elevado para a detecção e a avaliação de deformações.

Do mesmo modo, a observação das características dos padrões de drenagem das bacias, conforme Andrades Filho (2010), é uma das formas de análise de cunho qualitativo das redes de drenagem, que se refere à forma do traçado estabelecido pelo conjunto de canais. Esse traçado permite inferir sobre o condicionamento topográfico, litológico e estrutural da área onde se assentam os canais.

Pretender-se-á neste trabalho, relacionar a geomorfologia atual da área de estudo com os possíveis movimentos neotectônicos presentes na retaguarda do litoral paraibano, através da análise morfológica e morfométrica de sub-bacias do rio Mamuaba. Movimentos estes, que seriam explicados pelo reajuste das falhas que a abertura dos continentes africano e sulamericano provocou. Para tal, serão aplicados os índices morfométricos RDE (Relação Declividade-Extensão) e RFAV (Razão Fundo/Altura de Vale), e efetuadas análises qualitativas dos padrões da drenagem das sub-bacias selecionadas para o estudo, que serão as bacias dos rios Jangada, Mundo Novo e do Grilo, todas elas afluentes do rio Mamuaba, Zona da Mata Paraibana.

\section{Área de estudo}

O rio Mamuaba tem sua foz no baixo curso do rio Gramame, que deságua na praia de Barra de Gramame, seu limite está entre os municípios de João Pessoa e Conde - PB. O clima atuante na região é o tropical úmido, e as médias das temperaturas anuais situam-se em torno de 25으, apresentando índices pluviométricos que oscilam entre 1500 e $1700 \mathrm{~mm}$ (MELO, 2003).

As sub-bacias encontram-se em totalidade, dentro da área da carta topográfica Rio Mamuaba na escala de 1:25.000 (SB.25-Y-C-III-1-SO) confeccionada pela Superintendência de Desenvolvimento do Nordeste (SUDENE, 1974), perfazendo parte da Mesorregião da Zona da Mata Paraibana, Nordeste do Brasil (Figura 1). 


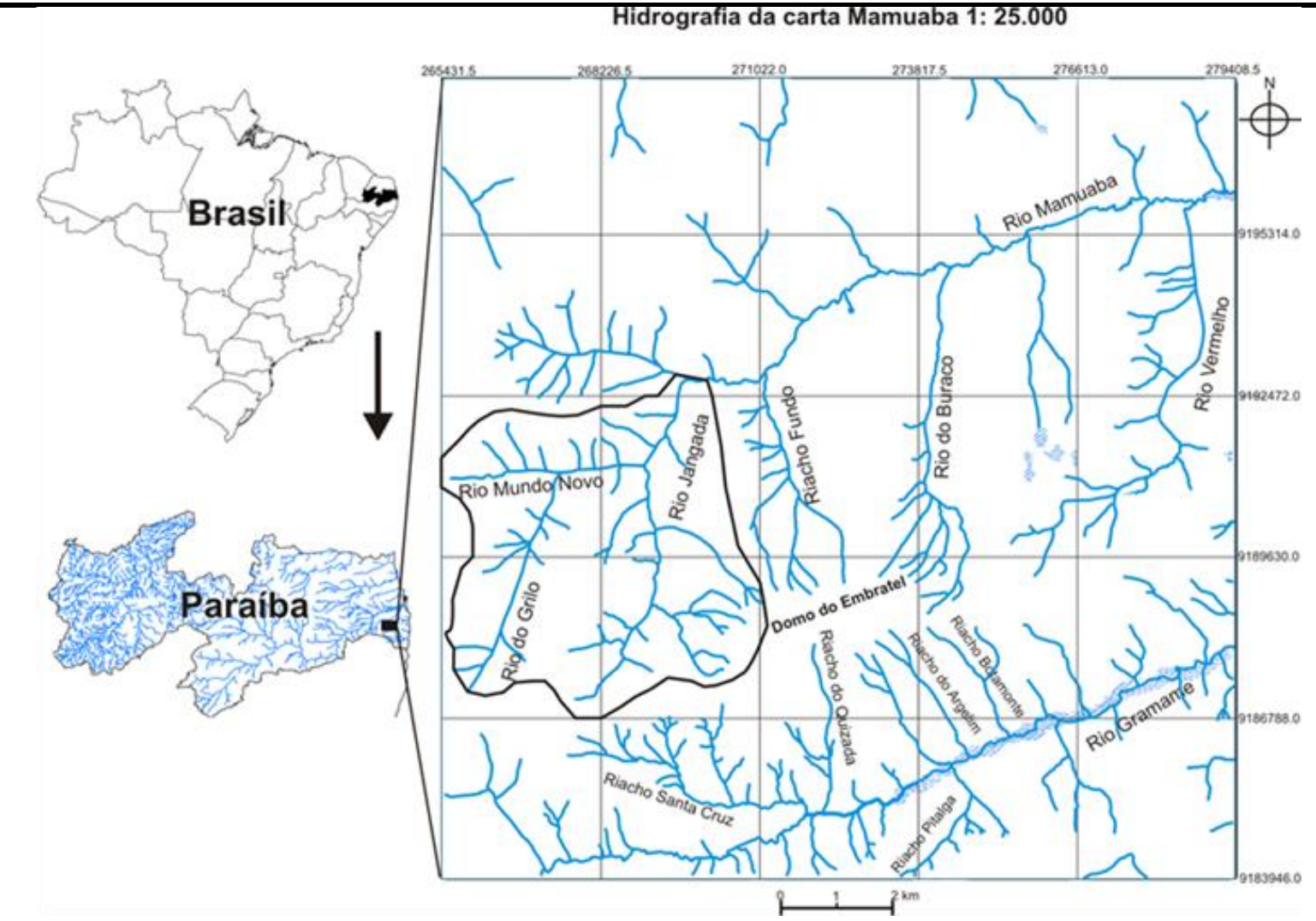

Figura 1- Localização das sub-bacias dos rios Jangada, Grilo e Mundo Novo, nos limites da Folha Rio Mamuaba 1: 25.000. Organização: Vinicius Ferreira de Lima.

\section{Contexto Geológico-Geomorfológico da Área}

O substrato geológico paraibano é formado predominantemente por rochas pré-cambrianas, as quais ocupam mais de $80 \%$ do seu território, sendo complementado por bacias sedimentares, rochas vulcânicas cretáceas, coberturas plataformais paleógenas/neógenas e formações superficiais quaternárias (BRASIL, 2002).

A área de estudo se assenta sobre a unidade litoestratigráfica denominada de Formação Barreiras - conjunto de sedimentos areno-argilosos mal consolidados de idade miocênica, que repousam de forma discordante, respectivamente de oeste para leste, sobre o embasamento cristalino pré-cambriano e sobre os sedimentos da bacia marginal Paraíba (ALHEIROS et al., 1988).

A bacia Paraíba é preenchida por sedimentos de fácies continentais e marinhas, reunidas sob a denominação de Grupo Paraíba, que por sua vez, é subdividido em três formações: Beberibe, Gramame e Maria Farinha (BRASIL, 2002), sendo a primeira clástica e as outras duas carbonáticas. Capeando o Grupo Paraíba, porém não fazendo parte dele, está a Formação Barreiras. 
No setor que corresponde ao baixo curso do rio Mamuaba é possível verificar o afloramento da Formação Beberibe em toda a extensão do canal fluvial (Brito Neves et al., 2009). Essa formação, quando em superfície, mostra-se difícil de ser distinguida da Formação Barreiras, pois além de os processos genéticos serem similares, os sedimentos apresentam grande semelhança granulométrica e textural, com grãos subangulosos a subarredondados, e seleção variando de moderada a fraca (FURRIER, 2007).

Devido a algumas falhas transversais presentes na bacia Paraíba, denominadas respectivamente Falha de Goiana e Falha de Itabaiana, que foram ativadas no Proterozoico, ela vem a ser subdividida em outras três sub-bacias, que são as sub-bacias de Olinda, Alhandra e Miriri, estando a área de estudo localizada na sub-bacia Alhandra (BARBOSA et al., 2004) (Figura 2).

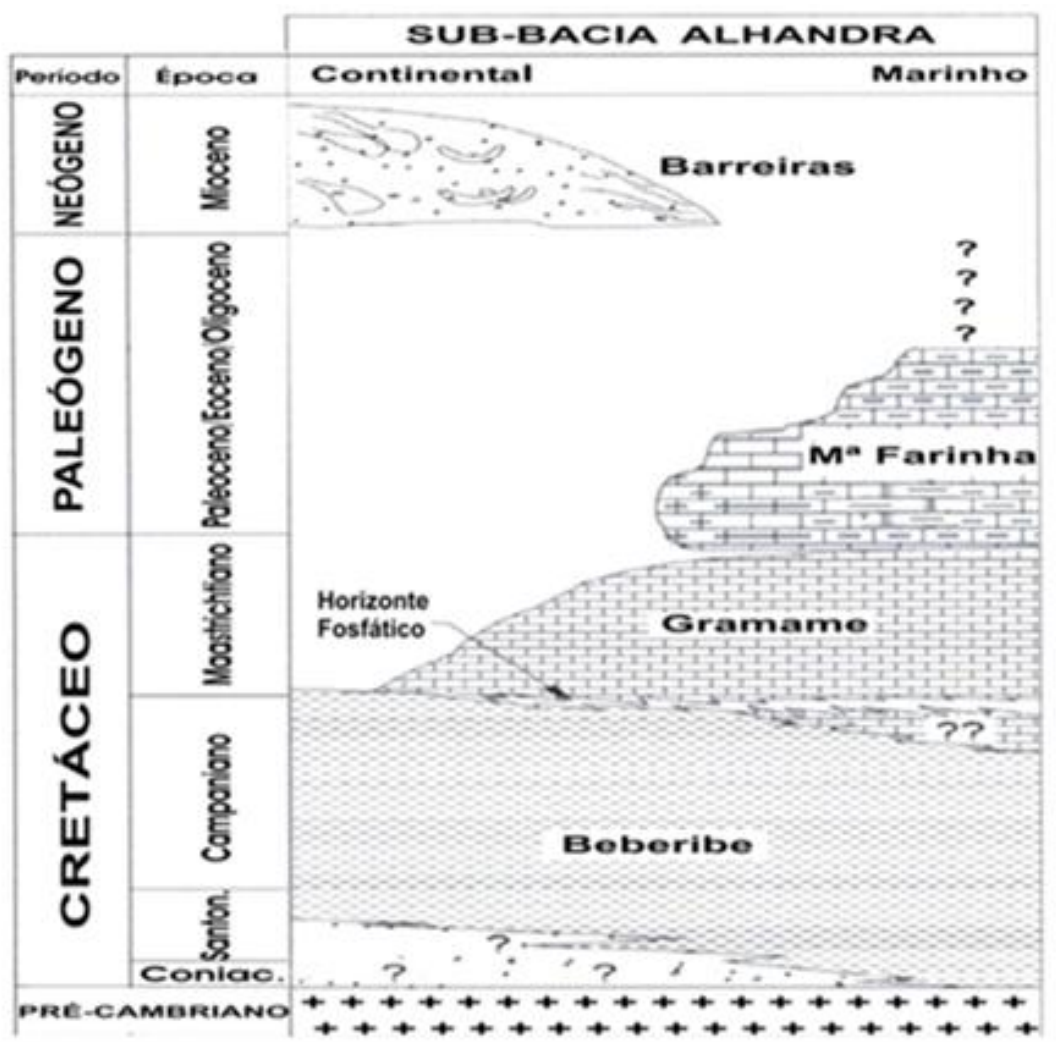

Figura 2 - Coluna estratigráfica da sub-bacia Alhandra (adaptado de Barbosa et al. 2004).

Brito Neves et al. (2009) deixa importantes contribuições acerca da estrutura geológica da região que compreende o rio Mamuaba, ele aponta a existência de falhamentos gravitacionais norte-sul, que influenciam diretamente na disposição do rio do Grilo e do rio Jangada, e condicionam o espessamento da Formação Beberibe no sentido do litoral. Rosseti et al. (2012) cita a existência de zonas de falha na bacia Paraíba que definem linhas de drenagens importantes, por exemplo, os rios Gramame, Mumbaba, Mamuaba e Paraíba. 
Quanto à Geomorfologia, predominam na área as estruturas dômicas (BRITO-NEVES et al, 2009), as planícies de inundação e os Tabuleiros Litorâneos. Segundo IBGE (1994), uma forma estrutural circular ou dômica se constitui em uma borda escarpada, geralmente de forma circular, resultante da erosão do seu entorno. Os domos ocorrem mais frequentemente em conjuntos de rochas metamórficas e raramente nas bacias sedimentares, portanto, as formas dômicas encontradas na área estão atreladas ao seu embasamento cristalino que também se encontra deformado por atividades tectônicas.

O domo da Embratel, que se encontra mais ou menos no centro da carta topográfica Rio Mamuaba 1:25.000, estrutura boa parte da rede de drenagem que compõe a carta. Dentre as sub-bacias escolhidas para a análise, o domo tem maior influência sobre a bacia do rio Jangada, que forma junto com outras bacias e afluentes do rio Gramame, uma drenagem centrífuga ou radial. Segundo Brito Neves et al. (2009), os movimentos direcionais estão sugeridos na formação dos domos presentes na área de estudo e adjacências, expondo o embasamento cristalino.

\section{MATERIAIS E MÉTODOS}

Para o estudo das sub-bacias Jangada, Grilo e Mundo Novo foi utilizada como ferramenta base a carta topográfica Rio Mamuaba 1:25.000 (SB.25-Y-C-III-1-SO), com equidistância das curvas de nível de $10 \mathrm{~m}$, o que fornece uma excelente precisão. Essa carta abarca, em totalidade, as sub-bacias selecionadas para a aplicação dos índices RDE (Relação DeclividadeExtensão) e RFAV (Razão Fundo/Altura de Vale).

Utilizando técnicas de geoprocessamento e sensoriamento remoto foi possível realizar o estudo das sub-bacias em laboratório, através da análise de imagens de satélite, de cartas temáticas produzidas e da carta topográfica. Desse modo, com os materiais cartográficos em mãos procedeu-se da seguinte forma: primeiramente, foi realizada a digitalização da carta Mamuaba, e logo após, ela foi vetorizada em software específico, empregando para este trabalho, o procedimento da vetorização manual, que é aquele em que o operador tem total controle sobre o traçado estabelecido com o mouse, exigindo precisão para que os resultados fossem os mais fieis possíveis.

Posteriormente, os produtos vetoriais gerados foram exportados para o software Spring 5.2 (Sistema de Processamento de Informações Georreferenciadas), que é um Sistema de Informações Geográficas (SIG) produzido e disponibilizado de forma gratuita no Brasil pelo 
INPE (Instituto Nacional de Pesquisas Espaciais). E neste SIG foram realizadas as análises morfológica e morfométrica das sub-bacias em estudo, através da reprodução de um Modelo Digital de Elevação do terreno (MDT) e de mapas temáticos de altimetria e declividade.

\section{Índice RDE (Relação Declividade-Extensão)}

O índice Relação declividade-extensão (RDE) foi proposto inicialmente por Hack (1973), conhecido como índice SL (Relação Slope vs. Lenght). Segundo Etchebehere et. al. (2006) este índice é um indicador sensível de mudanças na declividade do canal fluvial, que podem estar associadas a desembocaduras de tributários, a diferentes resistências à erosão hidráulica do substrato rochoso e/ou à atividade tectônica.

Para calcular o índice RDE, elege-se o rio de maior extensão e hierarquia fluvial da bacia e aplica-se o cálculo de RDE total, logo após, dividem-se os seguimentos do rio em tamanhos semelhantes e calcula-se o RDE trecho em cada um dos seguimentos. Conforme Martinez (2005), as fórmulas a serem utilizadas para os cálculos de ambos são, respectivamente:

$$
\begin{gathered}
R D E_{(\text {total })}=(\Delta H / L n L) \\
R D E_{(\text {trecho })}=(\Delta H / \Delta L) \times L
\end{gathered}
$$

Onde, no RDE total:

$\checkmark \Delta \mathrm{H}$ é a diferença altimétrica entre a cota localizada na cabeceira do rio e a cota localizada na foz do mesmo, em metros; e

$\checkmark$ LnL é o logaritmo natural da extensão total do curso de água em metros.

$\checkmark$ E no RDE trecho:

$\checkmark \Delta \mathrm{H}$ é a diferença altimétrica entre dois pontos selecionados no curso de água em metros;

$\checkmark \Delta \mathrm{L}$ é o comprimento sinuoso do trecho analisado em metros; e

$\checkmark$ L corresponde à extensão total (em linha reta) que vai da nascente do canal até o ponto final do trecho para onde o índice RDE está sendo calculado, em metros.

Índice RFAV (Relação Fundo/Altura de Vale) 
O índice Relação Fundo/Altura de Vale (RFAV), também descrito por alguns autores como índice VF (Valley floor), distingue vales que possuem superfície ampla no fundo de vales estreitos. Indicando se o rio está escavando ativamente o substrato rochoso, formando um vale em formato de "V", característica comum de regiões tectonicamente ativas e soerguidas há pouco tempo, ou se está em fase de erosão fluvial das vertentes, geralmente em terras baixas, onde o soerguimento tectônico cessou há muito tempo, e formam vales suaves em formato de "U". Conforme Bull \& McFadden (1977), este índice é definido pela seguinte equação:

$$
R F A V=2 L f v /[(E d e-E f v)+(E d d-E f v)]
$$

Onde:

$\checkmark$ O elemento RFAV representa a razão entre a largura do fundo e a elevação do vale;

$\checkmark$ "Lfv" diz respeito ao valor da largura do fundo de vale;

$\checkmark$ "Ede" é a elevação do divisor do setor esquerdo do vale;

$\checkmark$ "Edd" é a elevação do divisor do setor direito do vale; e

$\checkmark$ "Efv" é o valor da média de elevação do fundo do vale.

Para a aplicação deste índice é recomendável selecionar alguns perfis que cortem o canal de maior expressão dentro da bacia, efetuando cortes transversais ao vale com um ângulo de mais ou menos 90 , escolhidos em locais previamente determinados. Em seguida, os valores encontrados através das operações métricas do software Spring 5.2, do modelo de elevação do terreno, e das cartas temáticas e topográfica, são lançados na fórmula acima e calcula-se o RFAV.

\section{RESULTADOS E DISCUSSÕES}

As sub-bacias dos rios Jangada, Mundo Novo e do Grilo posicionam-se no alto curso do rio Mamuaba, à retaguarda do litoral paraibano, sobre os sedimentos mal consolidados da Formação Barreiras. As sub-bacias dos rios Mundo Novo e Grilo são consideradas, segundo o sistema de Strahler (1952), como bacias de 2a ordem e o rio Jangada como de $3^{\text {a }}$ ordem. As bacias possuem padrões de drenagem atípicos para a litologia na qual elas estão assentadas - rochas sedimentares, apresentando padrões retilíneos, assimétricos e em treliça, propícios aos terrenos onde há presença de falhas e atividade tectônica recente. 


\section{Análise do padrão da rede de drenagem}

O padrão de uma rede de drenagem está intimamente ligado à evolução geológica pela qual determinado terreno passou ao longo do tempo. A bacia hidrográfica é um sistema inteiramente sensível às variações que advêm dos fenômenos climáticos, estruturais ou antrópicos, funcionando como uma testemunha dos processos geológicos ocorrentes na área sob a qual ela está assentada.

Por isso, as bacias constituem-se em ferramentas importantes para o estudo neotectônico, já que quando o terreno sofre qualquer alteração o seu padrão é reajustado às novas condições impostas. Andrades Filho (2010) expõe diversos tipos de padrões em redes de drenagem e aponta que eles podem apresentar feições em setores específicos que destoam do arranjo de seu conjunto, constituindo anomalias de drenagem.

A significância da análise de tais feições ocorre principalmente, quando o substrato litológico é homogêneo. Quando ocorre dessa forma, as anomalias são tidas como fortes evidências de controle tectônico. Nas sub-bacias em estudo as anomalias do padrão de drenagem são facilmente constatáveis (Figura 3).

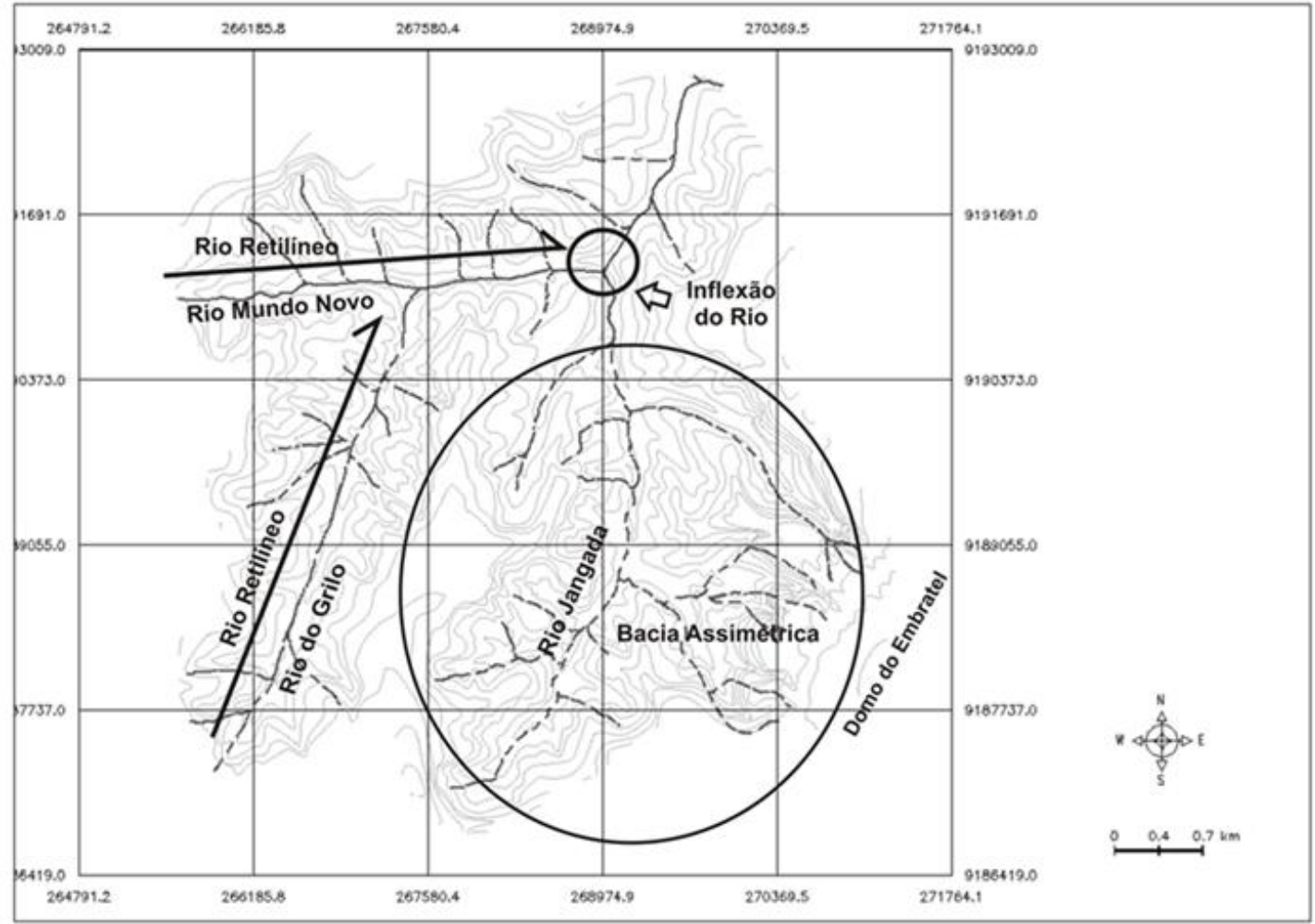

Figura 3 - Anomalias das sub-bacias dos rios Mundo Novo, Jangada e Grilo.

Podem-se encontrar cursos retilíneos, principalmente nos rios Mundo Novo e rio do Grilo, isso se coloca como uma anomalia, pois em terrenos que apresentam uma conformidade litológica o padrão normalmente seria o dendrítico. No rio Mundo Novo ocorre uma inflexão 
de quase 90 , formando um cotovelo no canal fluvial que provoca brusca mudança na direção do canal, que partiu da direção W - L para a direção SW - NE. No rio Jangada constata-se que a margem leste da bacia comporta canais bem mais avantajados que os da margem oeste, e com traços de drenagem treliça, que se considerado junto aos afluentes do rio Gramame, formam um padrão radial condicionado pelo domo do Embratel que se localiza, em grande parte, fora da área de estudo, no setor sudeste. Essa forte assimetria aponta grandes possibilidades de influência estrutural nesta sub-bacia. O rio do Grilo tem um amoldamento atípico em relação a um substrato litológico que é correspondente a uma camada de rochas sedimentares. A forma alongada e quase que completamente retilínea do rio principal e tributários assinala possível presença de falhas orientando o curso do rio, apontando também, a influência tectônica no relevo local.

\section{Altimetria e Declividade}

A carta de altimetria indica os níveis de altitude de determinada área, unindo os pontos de altitude semelhante, transformando a representação do terreno original em faixas de classes temáticas, que identificam em que altitude estão dispostos os diversos compartimentos que compõem a área.

O mapa de altimetria das sub-bacias em estudo indica uma grande variação topográfica adjacente aos rios. O rio do Grilo é o rio que apresenta maior entalhamento e retilinidade, suas nascentes estão entre as maiores faixas de altitude - de 100 a $180 \mathrm{~m}$. A bacia do rio Jangada, sendo a bacia de maior assimetria, possui em sua margem direita afluentes bem mais avantajados que os do lado esquerdo, compreendendo suas nascentes em altitudes que vão de 140 a 180 m no lado direito e de 80 a 120 m no lado esquerdo, indicando que houve possível basculamento nesta sub-bacia. O rio mundo é o rio que possui as cotas de altimetria mais baixas, nascendo em altitudes entre $60-120 \mathrm{~m}$, e desaguando no rio Mamuaba a $40-60$ m (Figura 4). 


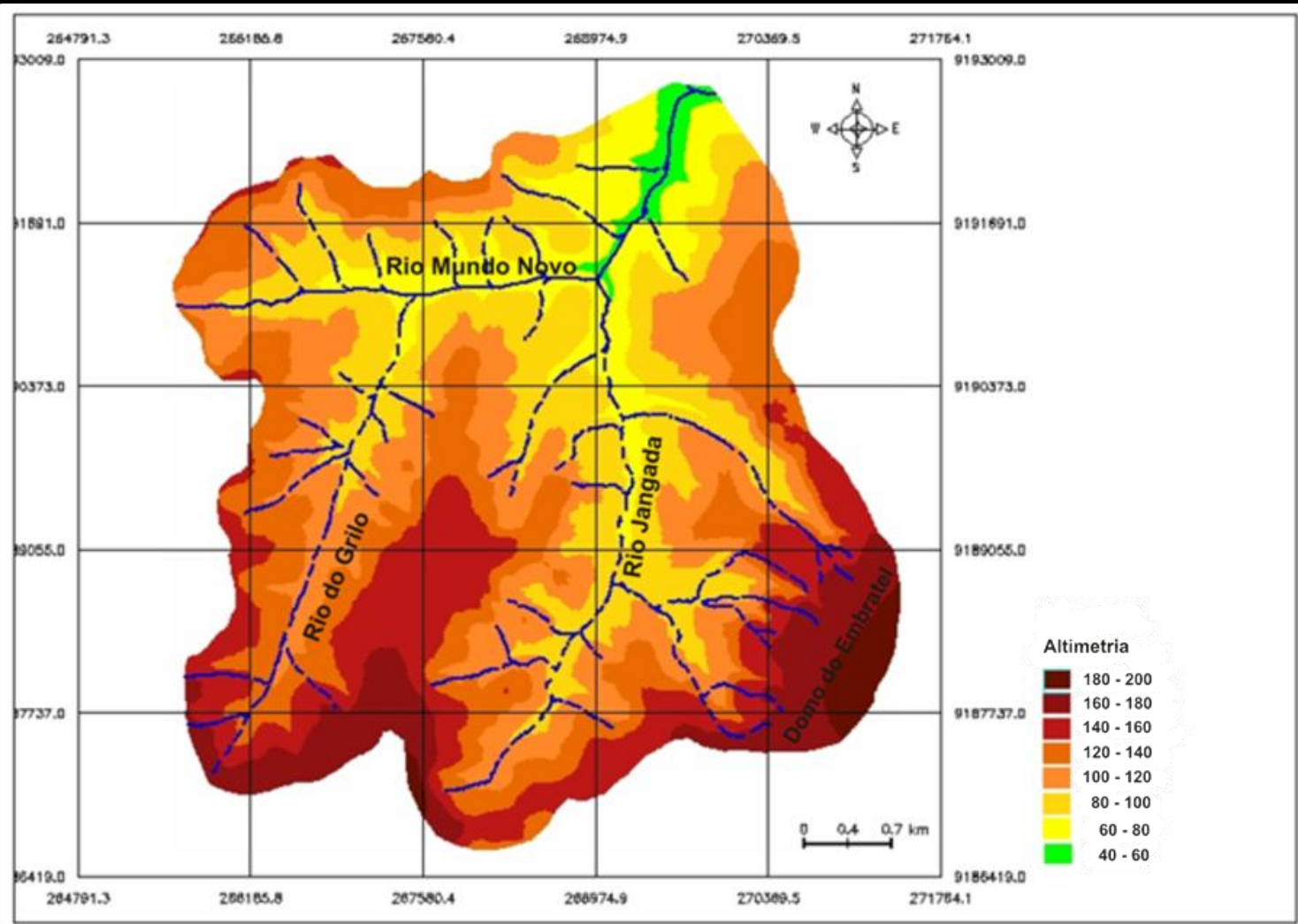

Figura 4 - Mapa de Altimetria das sub-bacias Rio do Grilo, Jangada e Mundo Novo. Organização: Tamires Silva Barbosa.

A definição das classes de declividades usadas neste trabalho foi baseada em Herz e De Biasi (1989), que amarraram essas classes a limites usados internacionalmente, bem como a trabalhos desenvolvidos por institutos de pesquisa nacionais e a leis vigentes no Brasil. Essas classes foram especificadas da seguinte forma:

$\checkmark<12 \%$ : Faixa que define o limite máximo para o emprego de mecanização na agricultura;

$\checkmark 12$ - 30\%: A Lei Federal no 6.766/1979 limita em 30\% de declividade a urbanização sem restrições;

$\checkmark 30$ - 47\%: A Lei Federal no 4.771/1965 (Código Florestal) limita em 47\% de declividade o corte raso da vegetação;

$\checkmark 47$ - 100\%: Nesse intervalo de declividade, o Código Florestal proíbe a derrubada de floresta sem um regime de utilização racional que vise a rendimentos permanentes;

$\checkmark$ 100\%: É considerada, pelo Código Florestal, área de preservação permanente, apenas sendo admitida a supressão total ou parcial da vegetação com prévia autorização do Poder Público Federal, quando for necessária a execução de obras, planos, atividades ou projetos de utilidade pública ou interesse social. 
O mapa de declividade gerado mostra que área comporta declividades de até $100 \%$ na margem direita da sub-bacia do rio Jangada, nas próximidades do domo da Embratel, demonstrando a grande influência do relevo dômico para a rede de drenagem da área. Em todas as outras sub-bacias predominam as declividades de $12-30 \%$ (Figura 5).

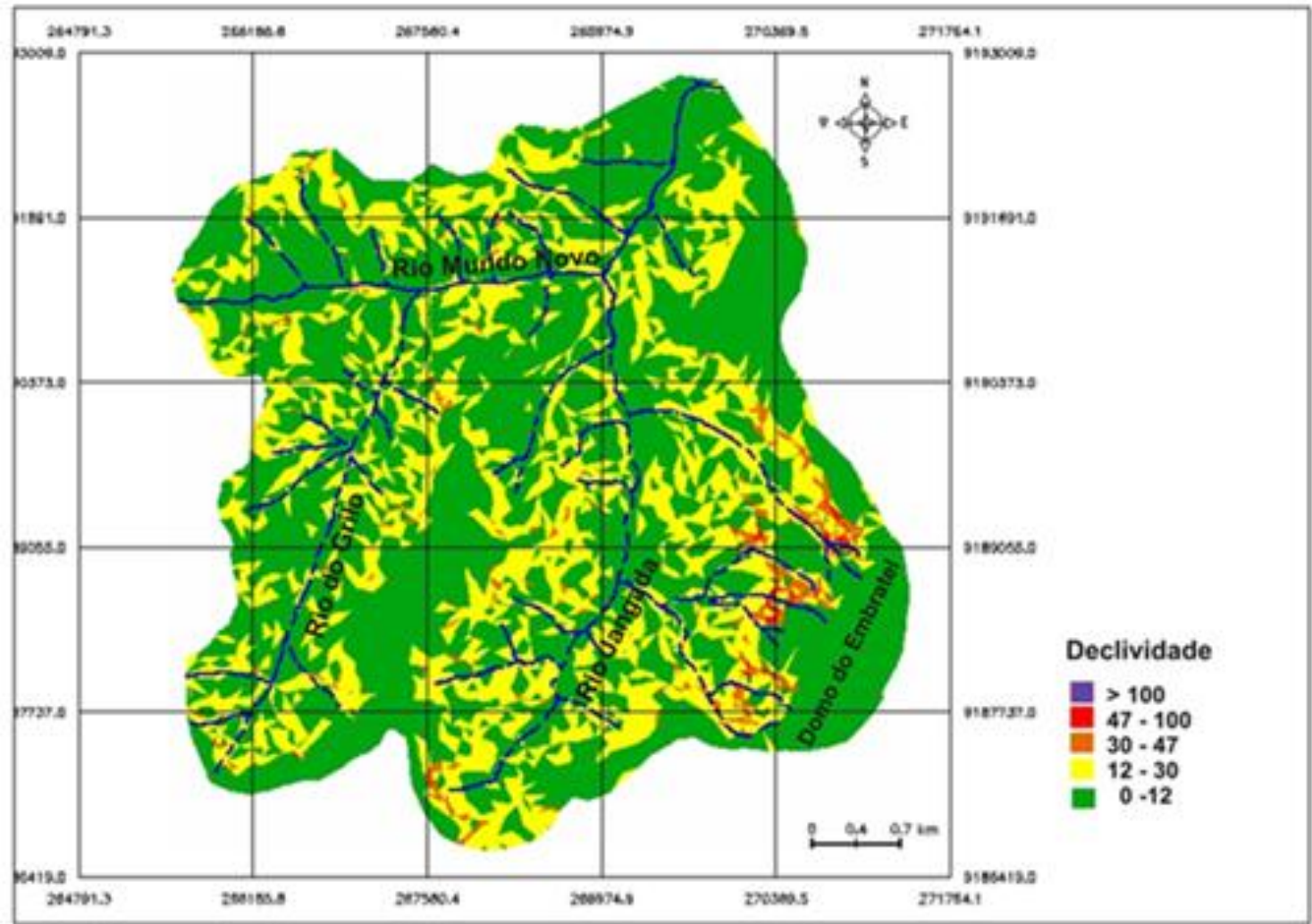

Figura 5 - Mapa de Declividade das sub-bacias Rio do Grilo, Jangada e Mundo Novo. Organização: Tamires Silva Barbosa

\section{Análise Morfométrica}

\section{ÍNDICE RDE (RELAÇÃO DECLIVIDADE-EXTENSÃO)}

Existem duas formas de aplicação do índice RDE: o RDE trecho e o RDE total. O RDE trecho é utilizado para o cálculo de pequenas extensões nas quais o rio principal está sendo dividido. O índice RDE total é aplicado para toda a extensão do curso, da nascente até a foz do rio que se deseja verificar. O valor do RDE real, aquele que será utilizado na análise final acerca de influência tectônica, é dado pela divisão do valor do RDE trecho pelo valor do RDE total do curso que está sendo analisado. 
O RDE total foi aplicado nos cursos principais das três sub-bacias, e para a aplicação do RDE trecho foram definidos previamente três segmentos de proporções mais ou menos semelhantes ao longo de cada curso do rio principal de cada sub-bacia (Figura 6).

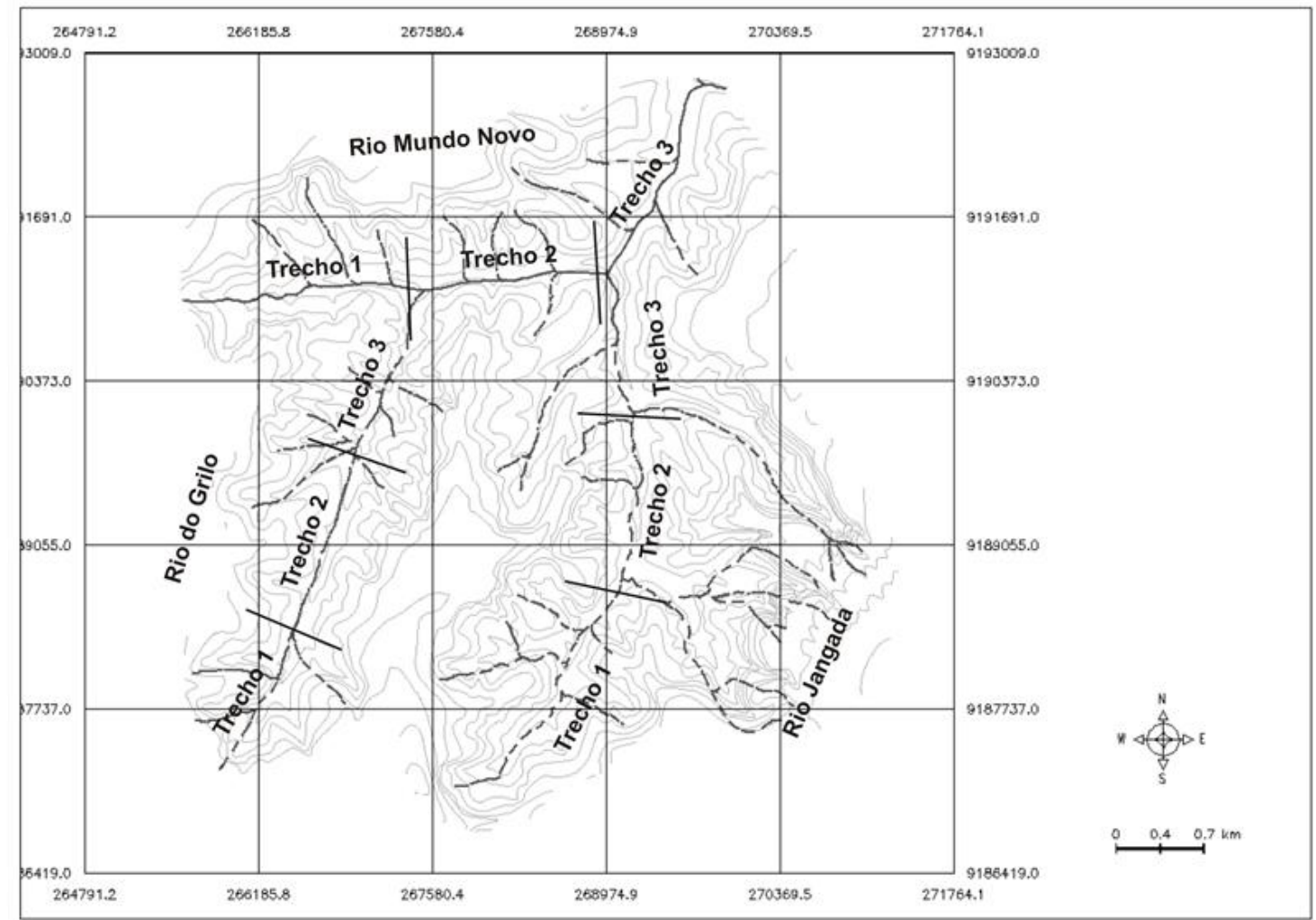

Figura 6 - Trechos escolhidos para cálculos de RDE. Organização: Tamires Silva Barbosa.

Para avaliar os valores de RDE adotou-se como base o trabalho de Andrades Filho (2010), onde ele ressalta que os segmentos considerados anômalos são os que obtêm RDE real maior ou igual a 2. Também foi consultado o trabalho de Seeber e Gornitz (1983), que subdividem os resultados anômalos de RDE em duas categorias: as anomalias de $2^{\text {a }}$ ordem, referentes aos índices compreendidos entre os limiares 2 a 10, e as anomalias de 1a ordem, referentes aos valores iguais ou superiores a 10.

A obtenção do índice RDE trecho e RDE total nas sub-bacias consideradas apontou que todos os seguimentos analisados apresentam altos valores de RDE. As Tabelas 1, 2 e 3 mostram um resumo das variáveis morfométricas encontradas nos cursos dos rios Jangada, Mundo Novo e do Grilo, bem como os resultados de RDE trecho, total e real.

O rio Jangada, conforme os dados abaixo, apresenta RDE total no valor de 9,25 , considerado por Seeber e Gornitz (1983) como uma anomalia de $2 \underline{a}$ ordem por apresentar valor inferior a 10. Em relação aos seus trechos, tem-se que os fragmentos 1 e 3 detém, assim, como o 
curso total, altos valores de RDE (>4), e o trecho 2, apesar de possuir um valor bem mais baixo, ainda é considerado anômalo por ser >2 (Tabela 1).

Tabela 1 - Variáveis morfométricas do rio Jangada

\begin{tabular}{ccccc}
\hline Trechos & Rio Jangada & Trecho 1 & Trecho 2 & Trecho 3 \\
\hline Cota Superior $(\mathrm{m})$ & 138,8 & 138,8 & 90 & 80 \\
Cota Inferior $(\mathrm{m})$ & 60 & 90 & 80 & 60 \\
Diferença Altimétrica (m) & 78,8 & 48,8 & 10 & 20 \\
Extensão do Trecho (m) & - & 2353 & 1420 & 1230 \\
Extensão Total (m) & 4986 & 2133 & 3315 & 4312 \\
RDE $_{\text {trecho }}$ & - & 44,23 & 23,34 & 70,11 \\
RDE $_{\text {total }}$ & 9,25 & 9,25 & 9,25 & 9,25 \\
RDE & $\mathbf{9 , 2 5}$ & $\mathbf{4 , 7 8}$ & $\mathbf{2 , 5 2}$ & $\mathbf{7 , 5 7}$ \\
\hline
\end{tabular}

Fonte: Pesquisa direta (2013)

No rio Mundo Novo, o valor resultante do cálculo do RDE total $(7,81)$, também é dado como uma anomalia de 2a ordem, com valor inferior a 10. Em relação aos seus trechos, o que foi avaliado como mais irregular foi o trecho 1 , com valor de $\operatorname{RDE}$ trecho de 6,23, quase alcançando o índice RDE total do rio. Os trechos 2 e 3 não apresentam valores tão altos, entretanto, não representam normalidade no padrão da drenagem do rio, pois constituem valores acima de 2 (2,88 e 2,29), portanto, anômalos (Tabela 2$)$.

Tabela 2 - Variáveis morfométricas do rio Mundo Novo

\begin{tabular}{ccccc}
\hline Trechos & Rio Mundo Novo & Trecho 1 & Trecho 2 & Trecho 3 \\
\hline Cota Superior $(\mathrm{m})$ & 120 & 120 & 70 & 60 \\
Cota Inferior $(\mathrm{m})$ & 53 & 70 & 60 & 53 \\
Diferença Altimétrica (m) & 67 & 50 & 10 & 7 \\
Extensão do Trecho (m) & - & 1975 & 1513 & 1771 \\
Extensão Total (m) & 5273 & 1923 & 3412 & 4528 \\
RDE trecho & - & 48,68 & 22,55 & 17,89 \\
RDE $_{\text {total }}$ & $\mathbf{7 , 8 1}$ & 7,81 & 7,81 & 7,81 \\
RDE & $\mathbf{7 e a l}$ & $\mathbf{6 , 8 1}$ & $\mathbf{2 , 8 8}$ & $\mathbf{2 , 2 9}$ \\
\hline
\end{tabular}

Fonte: Pesquisa direta (2013)

O rio do Grilo é o rio de menor extensão em relação aos demais, porém, foi dele que derivou o mais alto valor de RDE total -9,57. Este valor chega quase àquele que seria considerado como anomalia de 1a ordem (10). Dos seus trechos, o fragmento que apontou maior anormalidade foi o trecho 3 com valor de 7,64 (Tabela 3).

Tabela 3 - Variáveis morfométricas do rio do Grilo 


\begin{tabular}{ccccc}
\hline Trechos & Rio do Grilo & Trecho 1 & Trecho 2 & Trecho 3 \\
\hline Cota Superior $(\mathrm{m})$ & 150 & 150 & 120 & 96 \\
Cota Inferior $(\mathrm{m})$ & 70 & 120 & 96 & 70 \\
Diferença Altimétrica $(\mathrm{m})$ & 80 & 30 & 24 & 26 \\
Extensão do Trecho $(\mathrm{m})$ & - & 1298 & 1501 & 1488 \\
Extensão Total $(\mathrm{m})$ & 4265 & 1277 & 2721 & 4187 \\
RDE $_{\text {trecho }}$ & - & 29,51 & 43,50 & 73,15 \\
RDE $_{\text {total }}$ & 9,57 & 9,57 & 9,57 & 9,57 \\
RDE $_{\text {Real }}$ & $\mathbf{9 , 5 7}$ & $\mathbf{3 , 0 8}$ & $\mathbf{4 , 5 4}$ & $\mathbf{7 , 6 4}$ \\
\hline
\end{tabular}

Fonte: Pesquisa direta (2013)

\section{ÍNDICE RFAV (RAZÃO FUNDO/ALTURA DE VALE)}

Os altos valores de RFAV em determinado canal são atribuídos, geralmente, a vales em forma de " $U$ " ou vales abertos, que ocorre em canais sobrepostos às terras baixas, havendo predomínio de intemperismo químico do rio sobre as vertentes, criando longas planícies de inundação. Os baixos valores de RFAV referem-se a vales em forma de "V" ou vales encaixados, que indicam processos de incisão do rio, estes são comumente associados a soerguimentos tectônicos.

Se o cálculo do RFAV resulta em valores $<1$ ele indica que a área tem grandes possibilidades de ter passado por soerguimento tectônico recente, já os valores $>1$ sugerem que a atividade tectônica na região em que o rio está situado já cessou há longo período de tempo (ANDRADES FILHO, 2010).

Foram selecionados seis perfis transversais aos rios para aplicação do RFAV nas sub-bacias, sendo dois perfis de cada sub-bacia, cortando paralelamente o seu rio principal. Esses perfis foram delimitados por dois divisores de água em lados antagônicos da bacia, tendo como valores de referência curvas de nível e pontos cotados da carta topográfica Rio Mamuaba 1:25.000 e da grade de altimetria gerada por interpoladores no software SPRING 5.2 (Figura 7). 


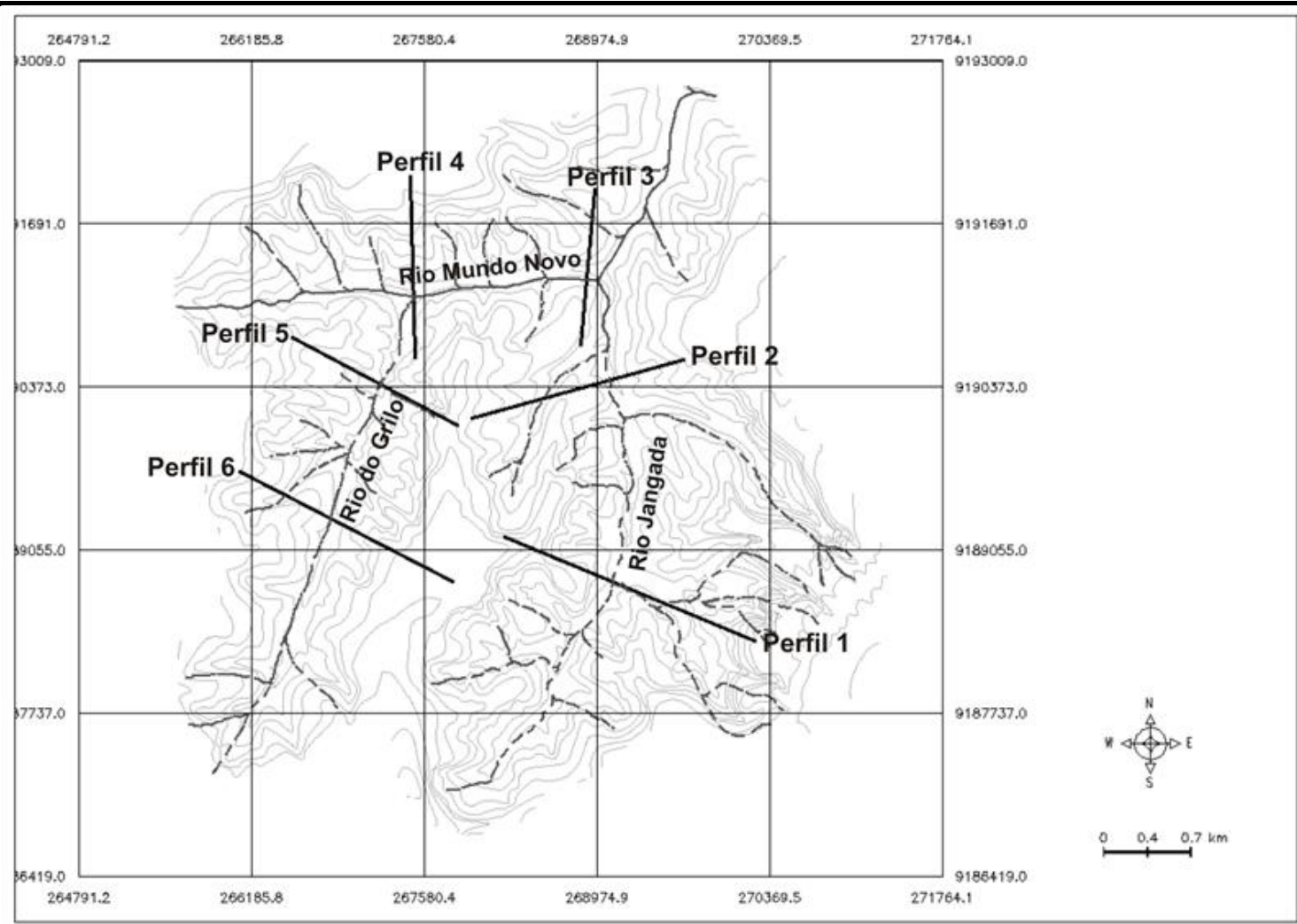

Figura 7 - Perfis selecionados para o RFAV. Organização: Tamires Silva Barbosa.

Os resultados alcançados no cálculo do RFAV também indicam forte influência de tectônica recente, pois somente um dos seis perfis considerados apresenta valor de RFAV $>1$, que é o perfil 5. Como mostram os valores na Tabela 4, o perfil 3 foi aquele que obteve o valor mais baixo $-0,08$, isto mostra uma irregularidade na relação entre o fundo e altura de vale do rio apresentando valor extremamente baixo para uma adjacência de uma margem continental do tipo passiva. Os perfis 1, 2, 4 e 6 também apresentam valores baixíssimos de RFAV $\leq 0,5$, evidenciando um possível soerguimento recente da área.

Tabela 4 - Valores considerados para efetivação do cálculo RFAV.

\begin{tabular}{ccccccc}
\hline & Perfil 1 & Perfil 2 & Perfil 3 & Perfil 4 & Perfil 5 & Perfil 6 \\
Largura do fundo & $158.7 \mathrm{~m}$ & $74.3 \mathrm{~m}$ & $66 \mathrm{~m}$ & $183 \mathrm{~m}$ & $39 \mathrm{~m}$ & $130 \mathrm{~m}$ \\
Elevação lado direito & $160 \mathrm{~m}$ & $110 \mathrm{~m}$ & $80 \mathrm{~m}$ & $90 \mathrm{~m}$ & $130 \mathrm{~m}$ & $157 \mathrm{~m}$ \\
Elevação lado esquerdo & $140 \mathrm{~m}$ & $120 \mathrm{~m}$ & $77 \mathrm{~m}$ & $138 \mathrm{~m}$ & $120 \mathrm{~m}$ & $140 \mathrm{~m}$ \\
Elevação do fundo do vale & $90 \mathrm{~m}$ & $73 \mathrm{~m}$ & $73 \mathrm{~m}$ & $70 \mathrm{~m}$ & $80 \mathrm{~m}$ & $105 \mathrm{~m}$ \\
Resultados RFAV & $\mathbf{0 , 3 7}$ & $\mathbf{0 , 5 6}$ & $\mathbf{0 , 0 8}$ & $\mathbf{0 , 2 4}$ & $\mathbf{1 , 1 5}$ & $\mathbf{0 , 3 3}$ \\
\hline
\end{tabular}

Fonte: Pesquisa direta (2013)

\section{CONCLUSÕES}

Pôde-se obter, através deste estudo, um melhor conhecimento da morfologia e morfometria da região que compreende as sub-bacias dos rios Jangada, Mundo Novo e do Grilo, 
considerando as formas dos padrões de drenagem da bacia, bem como os seus atributos morfométricos.

Por meio dos produtos cartográficos e da utilização do software SPRING 5.2 foi possível realizar a efetivação dos cálculos dos índices morfométricos RDE (Relação DeclividadeExtensão) e RFAV (Relação Fundo/Altura de Vale) nas sub-bacias designadas.

Com a obtenção dos dados morfométricos e suas devidas interpretações foi possível constatar a provável presença de atividades neotectônicas na área de estudo, principalmente pelos altíssimos valores de RDE total dos cursos analisados e pelos resultados obtidos no RFAV, resultados estes, bastante expressivos para uma retaguada de margem continental do tipo passiva.

Os índices RDE e RFAV, apesar de mostrarem boa eficácia em relação aos estudos que abordam as gêneses das mudanças ocorrentes nos perfis dos canais fluviais, ainda são pouco utilizados no Brasil, e devem ser estendidos a outras porções do território brasileiro, principalmente aquelas localizadas nas proximidades da margem continental brasileira. Estudos de cunho geomorfológico realizados nessas regiões e que excluíram por completo as evidências de atividades de tectônica recente devem ser revistos sobre a óptica de que a margem continental brasileira e sua retaguarda apresentam feições geomorfológicas e padrões de rede de drenagem impossíveis de serem atrelados única e exclusivamente ao fator climático.

\section{REFERÊNCIAS}

ALHEIROS. M. M.; LIMA FILHO, M. F.; MONTEIRO, F. A. J.; OLIVEIRA FILHO, J. S. Sistemas deposicionais na Formação Barreiras no Nordeste Oriental. In: CONGRESSO BRASILEIRO DE GEOLOGIA, 35., 1988, Belém. Anais... Belém: SBG, 1988. v. 2, p. 753-760.

ANDRADES FILHO, C. O. Análise morfoestrutural da porção central da Bacia Paraíba (PB) a partir de dados MDE-SRTM e ALOS-PALSAR FBD. Dissertação de Mestrado em Sensoriamento Remoto, Instituto Nacional de Pesquisas Espaciais - São José dos Campos: INPE. 150p. 2010.

BARBOSA, J. A.; SOUZA, E. M.; LIMA FILHO, M.F.; NEUMANN, V. H. A estratigrafia da Bacia Paraíba: uma reconsideração. Estudos Geológicos, v. 13: 89-198. 2004

BARRELLA, W.; PETRERE-JR., M.; SMITH, W. S.; MONTAGE, L. F. A. As relações entre as matas ciliares os rios e os peixes. In: Rodrigues, R. R. \& Leitão Filho, H. F. (Ed.) Matas ciliares: conservação e recuperação. 2. ed. São Paulo: USP. 2001.

BRASIL. Ministério de Minas e Energia. Geologia e recursos minerais do Estado da Paraíba. Recife: CPRM, 142 p. 2002. 
BRITO NEVES, B. B.; ALBUQUERQUE, J. P. T.; COUTINHO, J. M. V.; BEZERRA, F. H. R. Novos Dados Geológicos e Geofísicos para a Caracterização Geométrice Estratigráfica da Sub-bacia de Alhandra (Sudeste da Paraíba). Geologia USP - Série Científica, v. 9: 63-87. 2009.

CHRISTOFOLETTI, A. Geomorfologia. São Paulo: Edgard Blücher/EDUSP. 1980.

ETCHEBeHERE, M. L. C.; SAAD, A. R.; CASADO, F. C.; FUlFARO, V. J.; PERINOTTO, J. A. J. Aplicação do índice Relação Declividade-Extensão (RDE) na bacia do Rio do Peixe (SP) para detecção de deformações neotectônicas. Revista de Geociências USP, v. 4: 43-56. 2004.

ETCHEBEHERE, M. L. C.; SAAD, A. R.; SANTONI, G. C.; CASADO, F. C.; FULFARO, V. J. Detecção de prováveis deformações neotectônicas no vale do Rio do Peixe, região ocidental paulista mediante aplicação de índices RDE (Relação Declividade-Extensão) em segmentos de drenagem. Revista de Geociências USP, v. 25: 271-289. 2006.

FURRIER, M. Caracterização geomorfológica e do meio físico da Folha João Pessoa 1:100.000. 2007. Tese (Doutorado) - Faculdade de Filosofia, Letras e Ciências Humanas. São Paulo: USP. 213p. 2007.

HACK, J. T. Stream-profile analysis and stream gradient index. U.S. Geol. Survey, Jour. Research, v. 1, n. 4: 421-429. 1973.

HASUI, Y. Neotectônica e Aspectos Fundamentais da Tectônica Ressurgente no Brasil. SBG/MG. Workshop sobre Neotectônica e Sedimentação Cenozoica Continental no Sudeste Brasileiro, Belo Horizonte, 1: 1-31. 1990.

HERZ, R.; DE BIASI, M. Critérios e legendas para macrozoneamento costeiro. Ministério da Marinha/Comissão Interministerial para os Recursos do Mar. Brasília: MM. 1989.

IBGE. Manual Técnico de geomorfologia/Bernardo de Almeida Nunes (coordenadores). - Rio de Janeiro: IBGE, Departamento de Recursos Naturais e Estudos Ambientais, 113 p., no.5. ISNN 0103-9598. 1994.

MARTINEZ, M. Aplicação de parâmetros morfométricos de drenagem na bacia do rio Pirapó: o perfil longitudinal. Dissertação (Mestrado em Geografia) -Departamento de Geografia do Centro de Ciências Humanas, Letras e Artes. Maringá: da Universidade Estadual de Maringá, 96 p. 2005.

MELO, A. S. T. de. Paraíba: desenvolvimento econômico e a questão ambiental. João Pessoa: Editora Grafset. 2003.

ROSSETTI, D. F.; GOES, A. M.; BEZERRA, F. H. R.; VALERIANO, M. M.; BRITO NEVES, B. B.; OCHOA, F. L. Contribution to the stratigraphy of the onshore Paraiba Basin, Brazil. An. Acad. Bras. Ciênc., vol.84, no.2: 313-334. ISSN 0001-3765. 2012.

SAADI, A. Neotectônica da Plataforma Brasileira: esboço e interpretação preliminares Geonomos. Revista de Geociências da UFMG, Belo Horizonte, v. 1, n. 1: 1-15. 1993.

SEEBER, L.; GORNITZ, V. River profiles along the Himalayan arc as indicators of active tectonics. Tectonophysics, Amsterdam, v. 92: 335-367. 1983. 
SUDENE. Superintendência de Desenvolvimento do Nordeste. Folha Santa Rita SB. 25-Y-CIII-1-SO (1:25.000). Recife: SUDENE, Carta Topográfica. 1974.

SUGUIO, K. 1999. Geologia do Quaternário e mudanças ambientais: (passado + presente = futuro?). São Paulo: Paulo's Comunicação e Artes Gráficas.

Artigo recebido em 26/05/2013.

Artigo aceito em 17/06/2013. 